\title{
Patterns of herpes simplex virus shedding over 1 month and the impact of acyclovir and HIV in HSV-2-seropositive women in Tanzania
}

\author{
Clare Tanton, ${ }^{1,2}$ Helen A Weiss, ${ }^{1}$ Jerome LeGoff, ${ }^{3}$ John Changalucha, ${ }^{2}$ Tim C Clayton, ${ }^{1}$ \\ David A Ross, ${ }^{1}$ Laurent Belec, ${ }^{4}$ Richard J Hayes, ${ }^{1}$ Deborah Watson-Jones ${ }^{1,5}$
}

\begin{abstract}
${ }^{1}$ London School of Hygiene and Tropical Medicine, London, UK ${ }^{2}$ National Institute for Medical Research (NIMR), Mwanza, Tanzania

${ }^{3}$ Laboratoire de Microbiologie, Hôpital Saint Louis, Paris, France ${ }^{4}$ Départment de Microbiologie, Laboratoire de Virologie, Hôpital Européen Georges Pompidou and Université Paris Descartes, Paris, France

${ }^{5}$ African Medical and Research Foundation (AMREF), Mwanza, Tanzania
\end{abstract}

\section{Correspondence to}

Dr Clare Tanton, Centre for Sexual Health and HIV Research, Research Department of Infection and Population Health, University College London, Mortimer Market Centre, off Capper Street, London WC1E 6JB, UK; c.tanton@ucl.ac.uk

Findings from this study have previously been presented at the 18th meeting of the International Society for Sexually Transmitted Disease Research (ISSTDR), London 2009 (Abstract no P4.15).

Accepted 3 May 2011 Published Online First 8 June 2011

\section{(D) UNLCKIA}

This paper is freely available online under the BMJ Journals unlocked scheme, see http://sti. bmi.com/site/about/unlocked. xhtml

\section{ABSTRACT}

Objectives Few studies have examined the frequency and duration of genital herpes simplex virus (HSV) shedding in sub-Saharan Africa. This study describes HSV shedding patterns among a sample of HSV-2seropositive women enrolled in a placebo-controlled trial of HSV suppressive therapy (acyclovir $400 \mathrm{mg}$ twice a day) in Tanzania.

Methods Trial participants were invited to participate in a substudy involving 12 clinic visits over 4 weeks. At each visit, cervical, vaginal and external skin swabs were taken and analysed for HSV DNA using inhouse real-time PCR

Results HSV shedding was mainly subclinical (90\%; 57/ 63 shedding days in the placebo arm). The most frequent shedding site was the external skin, but HSV DNA was detected from all three sites on $42 \%$ (27/63) of shedding days. In HIV-negative women, HSV DNA was detected on $3 \%(9 / 275)$ of days in the acyclovir versus $11 \%$ (33/ 309 ) in the placebo arm, while in HIV-positive women, detection was on $14 \%(23 / 160)$ versus $19 \%(30 / 155)$ of days, respectively.

Conclusions HSV shedding was common, varying greatly by individual. Shedding rates were similar to studies in African and non-African settings. Among HIVnegative women, shedding rates were lower in the acyclovir arm; however, acyclovir did not substantially impact on HSV shedding in HIV-positive women.

Herpes simplex virus (HSV) type 2, is the most frequent cause of genital ulcer disease. ${ }^{1}$ Infection is latent most of the time, but HSV reactivations, either clinical or subclinical, occur throughout an individual's life. ${ }^{2}{ }^{3}$ HSV shedding occurs more frequently in HIV-positive individuals. ${ }^{4-6}$

There are few studies of HSV shedding in sub-Saharan Africa. Some, ${ }^{5} 7$ but not all, ${ }^{8-11}$ suggest that shedding rates among women may be higher than in developed countries, possibly due to the presence of other co-factors such as sexually transmitted infections (STI) or vaginal cleansing practices. Bacterial vaginosis, highly prevalent in women from sub-Saharan Africa, has been associated with increased vaginal HSV DNA shedding. ${ }^{12}$

The WHO recommends administering antiherpes therapy as part of syndromic management in settings where herpes accounts for greater than $30 \%$ of genital ulcer disease, ${ }^{13}$ but recent randomised controlled trials of the impact of this strategy on ulcer healing have had mixed results. ${ }^{14-16} \mathrm{~A}$ more detailed understanding of
HSV shedding patterns may help interpret these findings and those of HSV suppressive therapy trials reporting no impact on HIV acquisition or transmission. ${ }^{17-19}$

In this study, we describe HSV shedding patterns and the effect of acyclovir and HIV on shedding over 1 month among a sample of HSV-2-seropositive women in Tanzania enrolled in a randomised placebo-controlled trial of HSV suppressive therapy.

\section{METHODS}

\section{Study participants and procedures}

This study was nested within a randomised placebo-controlled trial of acyclovir $400 \mathrm{mg}$ twice a day conducted in 19 communities in northwestern Tanzania (ISRCTN 35385041). Screening, randomisation and follow-up procedures for this trial have been described previously. ${ }^{17}$ The trial evaluated the effect of HSV suppressive therapy on HIV incidence in HIV-negative women and cervicovaginal HIV shedding in HIV-positive women. ${ }^{17} 20$

This study was conducted between August and October 2005 in two of the 19 trial communities, with the communities chosen for logistical reasons. Women were eligible if they were trial participants, had not withdrawn from study tablets, were healthy enough to participate, were not planning to move within the follow-up period and were attending their main trial 18-month follow-up visit in these two communities. Trial counsellors gave eligible women information about the substudy, and those interested in participating were given an enrolment appointment 2-6 weeks later.

Eligibility was re-assessed at the enrolment appointment. Additional eligibility criteria were an ability to understand the study and not planning to travel for one period of more than 4 days or for two periods of 3 days or more during the follow-up period. Women were enrolled following written or fingerprint consent.

A short interview collected information including current contraception and STI symptoms. A genital examination was performed, clinical findings were noted and three genital swabs were collected, one from each of the cervix and vagina as previously described ${ }^{21}$ and one from the external genitalia by rolling the swab over the clitoris, vulva and perianal area. Swabs were stored dry in separate tubes. An additional swab was taken from any genital ulcers. STI were treated syndromically according to Tanzanian national guidelines. Women were offered condoms. 
To avoid unblinding the field team to treatment allocation and HIV status, enrolment was monitored by the independent trial statistician who informed the team when sufficient participants had been enrolled, to give a minimum sample size of 15 women in each of four strata, ie, HIV-positive women on acyclovir/ placebo and HIV-negative women on acyclovir/placebo.

\section{Follow-up}

Women attended the study clinic three times per week and were followed for 4 weeks, for a maximum of 12 visits (including enrolment). At each visit, a genital examination was carried out and swabs were collected, as detailed above.

\section{Laboratory analyses}

Swabs were frozen at $-20^{\circ} \mathrm{C}$ immediately after collection and placed in a $-80^{\circ} \mathrm{C}$ freezer within 2 weeks. Lysis buffer was added to cervical, vaginal and external skin swabs before extraction to protect the nucleic acids. Tubes containing the swabs and lysis buffer were vortexed briefly, incubated at $56^{\circ} \mathrm{C}$ for $10 \mathrm{~min}$ and then vortexed briefly again. Swabs were transferred to the swab extraction tube system (Roche Molecular Diagnostics, Meylan, France) and centrifuged at $12000 \mathrm{rpm}$ for $1 \mathrm{~min}$. Recuperated fluid was added to the original tube. Nucleic acid extraction was carried out using the NucliSens EasyMag system (bioMérieux, Marcy l'Etoile, France). HSV DNA was quantified using an inhouse real-time PCR ${ }^{22}$ and the Applied Biosystems 7300 Realtime PCR System (Applied Biosystems, Courtaboeuf, France). Genital ulcer swabs were tested for Trephonema pallidum, HSV and Haemophilus ducreyi using multiplex PCR.

\section{Statistical methods}

As the main aim of this study was descriptive, no formal sample size calculation was carried out although it was intended to include at least 15 women in each of the four study strata from these two sites.

Data were double-entered and validated in dBase IV and analysed using Stata 10.

The threshold of quantification for HSV DNA was 110 copies per swab. Shedding quantities below this threshold were classed as undetectable. Viral load data were $\log _{10}$ transformed for analysis.

The main analysis is based on the overall 'shedding rate' in each strata, defined as the total number of samples with HSV detected divided by the total number of visits from which samples were available ('per visit' analysis). This provides the most consistent measure regardless of the number of swabs collected. ${ }^{23}$ Additional analyses included 'per woman' analyses in which the outcome is the percentage of visits when shedding was detected for each woman grouped into the following categories: none, less than $25 \%, 25 \%$ to less than $50 \%$ and $50 \%$ to less than $75 \%$.

Shedding was defined as clinical if it occurred on a day when ulcers or blisters were observed by the clinician at any site and subclinical if it occurred on a day when no ulcers or blisters were observed.

The association of acyclovir with HSV shedding rate ("per visit' analysis) was analysed with logistic regression using generalised estimating equations with an exchangeable correlation matrix, adjusting for within-woman clustering. Analysis of the 'per woman' outcomes used ordinal logistic regression. The per-visit analysis examines HSV shedding overall combining data from all women. In the per-woman analysis, we examine the persistence of HSV shedding from the perspective of an individual participant.
Adherence was estimated within the main trial by tablet count at each 3-month follow-up visit. Adherence for the 18-21-month follow-up period was used as an estimate for adherence within this 1-month substudy.

The study protocol was approved by the London School of Hygiene and Tropical Medicine ethics committee and the Medical Research Coordinating Committee of Tanzania. Within the main trial participants had access to voluntary counselling and testing for HIV and HIV-positive women were referred to the closest care and treatment centre for HIV. ${ }^{17} 20$

\section{RESULTS}

\section{Cohort recruitment and follow-up}

In total, 124 women were given information about the substudy at their 18-month follow-up visit. Appointments were accepted by $102(82 \%)$, of whom 78 (76\%) were enrolled. Participants had 12 scheduled visits, including enrolment, and 96\% (899/936) of potential visits were attended, with most women $(n=69 ; 88 \%)$ completing all visits. Data were analysed from 77 women attending two or more visits. Of these, 50 were HIV seronegative (24 randomly assigned to acyclovir and 26 to placebo) and 27 were HIV seropositive (14 randomly assigned to acyclovir and 13 to placebo). Two women were taking antiretroviral therapy.

\section{Study population characteristics}

Substudy participants were slightly older than trial participants not enrolled in the substudy (28.8 vs 27.3 years for HIV-negative and 30.0 vs 27.9 years for HIV-positive women). There were no other differences between these two groups including a self-reported history of genital ulcers.

The median age was 29 years (IOR 26-33) and over $60 \%$ of women were divorced, separated or widowed (table 1). A history of genital ulcers or blisters was reported by $30 \%$ of participants. Characteristics were broadly similar by both HIV status (table 1) and treatment arm (data not shown).

Estimated adherence during the 3-month period in which this study was nested was $90 \%$ or greater for $26 / 50$ (52\%) of HIVnegative participants and 13/27 (48\%) of HIV-positive participants. Overall, 24/38 (63\%) substudy women in the acyclovir arm had $90 \%$ or greater reported adherence compared with $15 / 39(38 \%)$ in the placebo arm $(p=0.03)$.

\section{Clinical symptoms and association with HSV shedding}

During follow-up, in $26 \mathrm{HIV}$-negative women on placebo there were three visits in which signs consistent with clinical HSV were present, in three different women. Only two were associated with cervicovaginal or perineal HSV DNA detection; ulcer swabs were not taken from either woman. One of the $13 \mathrm{HIV}$ positive women on placebo had a clinical herpetic episode lasting four visits, with HSV DNA detected at all visits. Ulcer swabs were HSV positive at the first three visits. There were no clinical HSV episodes in the $24 \mathrm{HIV}$-negative women on acyclovir and in 14 HIV-positive women on acyclovir, despite six visits (in two women) when signs consistent with clinical HSV were present, HSV DNA was detected on only one visit and from only one ulcer swab.

\section{Per-visit analysis of shedding}

Overall, HSV DNA was detected at 63 visits (14\%) in the placebo arm; 33 visits (11\%) in HIV-negative women and 30 visits (19\%) among HIV-positive women. On most of these visits $(57 / 63$; 90\%), no clinical signs were seen $(31 / 33$; $94 \%$ in HIV-negative and 26/30; $87 \%$ in HIV-positive women). Shedding was most frequently detected from the external 
Table 1 Key characteristics of substudy participants, by HIV-1 status at enrolment*

\begin{tabular}{|c|c|c|c|}
\hline Characteristic & $\begin{array}{l}\text { HIV seronegative } \\
(\mathrm{N}=50) \mathrm{n}(\%)\end{array}$ & $\begin{array}{l}\text { HIV seropositive } \\
(\mathrm{N}=27) \mathrm{n}(\%)\end{array}$ & $\begin{array}{l}\text { All participants } \\
(\mathrm{N}=77) \text { n }(\%)\end{array}$ \\
\hline \multicolumn{4}{|l|}{ Sociodemographic characteristics } \\
\hline Median age (IOR), years & $29(26-32)$ & $30(25-34)$ & $29(26-33)$ \\
\hline \multicolumn{4}{|l|}{ Marital status } \\
\hline Single & $6(12)$ & $4(15)$ & $10(13)$ \\
\hline Married/living as married & $16(32)$ & $4(15)$ & $20(26)$ \\
\hline Divorced/separated & $24(48)$ & $15(56)$ & $39(51)$ \\
\hline Widowed & $4(8)$ & $4(15)$ & $8(10)$ \\
\hline \multicolumn{4}{|l|}{ Behavioural characteristics } \\
\hline Median age at first sex (IQR), years & $16(15-18)$ & $16(15-17)$ & $16(15-18)$ \\
\hline $\begin{array}{l}\text { Median no of lifetime partners (IQR), } \\
\text { years }\end{array}$ & $4(3-5)$ & $6(4-20)$ & $5(3-7)$ \\
\hline \multicolumn{4}{|l|}{ No of times cleanses vagina per day } \\
\hline Does not cleanse & $20(40)$ & $9(33)$ & $29(38)$ \\
\hline $1-2$ & $13(26)$ & $8(30)$ & $21(27)$ \\
\hline$\geq 3$ & $17(34)$ & $10(37)$ & $27(35)$ \\
\hline \multicolumn{4}{|l|}{ Clinical characteristics } \\
\hline History of genital ulcers/blisters & $17(34)$ & $6(22)$ & $23(30)$ \\
\hline Episode of GUD in past year & $12(24)$ & $4(15)$ & $16(21)$ \\
\hline Using hormonal contraceptive $†$ & $23(46)$ & $17(63)$ & $40(52)$ \\
\hline \multicolumn{4}{|l|}{ Biological characteristics } \\
\hline $\begin{array}{l}\text { Geometric mean plasma HIV RNA } \\
\text { load } \neq(I Q R) \text {, copies/ml }\end{array}$ & - & $42046(7609,169085) \S$ & - \\
\hline Cervicovaginal HIV-1 RNA detected $\neq$ & - & $14(58)$ & - \\
\hline
\end{tabular}

vulval/perineal/perianal skin $(10 \%$ and $17 \%$ of visits in HIVnegative and HIV-positive women, respectively).

A similar proportion of shedding days involved shedding from all sites among HIV-negative (14/33; 42\%) and HIV-positive $(13 / 30 ; 43 \%)$ women. Most single-site shedding days involved the external skin (21/26; 81\% overall).

Among HIV-negative women, HSV DNA was detected less often in the acyclovir (3\%) than in the placebo arm $(11 \%$; OR 0.28 ; $95 \%$ CI 0.12 to 0.66 ; table 2) and the proportion of shedding days that were multisite was lower among women in the acyclovir arm (1/9 (11\%) vs 13/30 (42\%); $p=0.08)$. Among HIVpositive women, shedding rates were more similar in the two arms $(14 \%$ in the acyclovir arm; $19 \%$ in the placebo arm; OR 0.69 ; $95 \%$ CI 0.26 to 1.85 ; table 2 ). Similar reductions in shedding were seen at each anatomical site (table 2), although numbers were small.

Further analyses among HIV-negative participants stratified by estimated adherence found weak evidence for a stronger association between shedding and acyclovir therapy in those with estimated adherence of $90 \%$ or greater over the 3 -month period (6/191 vs 22/120, OR $0.14 ; 95 \%$ CI 0.05 to 0.43 ) compared with those with estimated adherence less than $90 \%$ or unknown (3/84 vs $11 / 189$, OR $0.61 ; 95 \%$ CI 0.18 to 2.09; $\mathrm{p}_{\text {interaction }}=0.085$ ). There were too few women for a similar analysis in HIV-positive women.

\section{Per-woman analysis of HSV shedding}

In the placebo arm, 13/26 (50\%) of HIV-negative women and 9/13 (69\%) of HIV-positive women had HSV DNA detected from at least one swab during follow-up. Figure 1A shows shedding patterns among these women. In HIV-negative and HIV-positive women, $58 \%$ and $75 \%$ of shedding episodes, respectively, lasted only one visit. Overall, $19 \%$ and $38 \%$ of HIV-negative and HIV-positive women, respectively, had two or more HSV shedding episodes during follow-up. Figure 1A illustrates the individual variability in HSV shedding. For example,

Table 2 Effect of aciclovir on overall and site specific shedding by HIV status

\begin{tabular}{|c|c|c|c|c|c|c|}
\hline & \multicolumn{3}{|c|}{ HIV negative } & \multicolumn{3}{|c|}{ HIV positive } \\
\hline & $\begin{array}{l}\text { Aciclovir n (\%) } \\
\text { (N=275) }\end{array}$ & $\begin{array}{l}\text { Placebo n (\%) } \\
(\mathrm{N}=309)\end{array}$ & $O R^{*}(95 \% \mathrm{Cl})$ & $\begin{array}{l}\text { Aciclovir n (\%) } \\
(\mathrm{N}=160)\end{array}$ & $\begin{array}{l}\text { Placebo n (\%) } \\
(\mathrm{N}=155)\end{array}$ & $O R^{*}(95 \% \mathrm{Cl})$ \\
\hline No of (\%) visits HSV DNA detect & & & & & & \\
\hline Any swab & $9(3)$ & $33(11)$ & 0.28 (0.12 to 0.66$)$ & $23(14)$ & $30(19)$ & $0.69(0.26$ to 1.85$)$ \\
\hline & \multicolumn{6}{|c|}{$\mathrm{p}_{\text {interaction }}$ (treatment and HIV status) $=0.17$} \\
\hline Cervical swabs & $3(1)$ & $16(5)$ & 0.20 (0.05 to 0.82$)$ & $15(9)$ & $15(10)$ & $0.97(0.29$ to 3.23$)$ \\
\hline & \multicolumn{6}{|c|}{$\mathrm{p}_{\text {interaction }}=0.22$} \\
\hline \multirow[t]{2}{*}{ Vulval/perineal/perianal swabs } & $3(1)$ & $31(10)$ & $0.10(0.03$ to 0.35$)$ & $17(11)$ & $26(17)$ & $0.59(0.18$ to 1.92$)$ \\
\hline & \multicolumn{6}{|c|}{$\mathrm{p}_{\text {interaction }}=0.05$} \\
\hline
\end{tabular}

*OR for the effect of aciclovir on HSV DNA detection compared with placebo. 
A Placebo arm
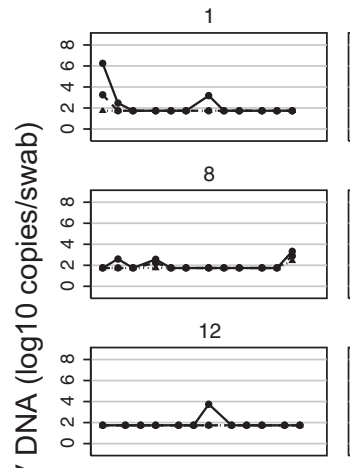

ज
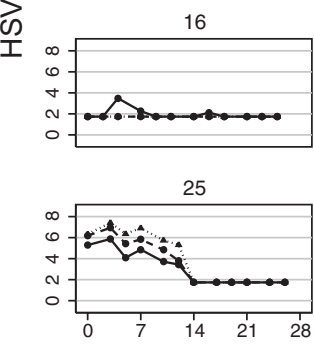

HIV Positive

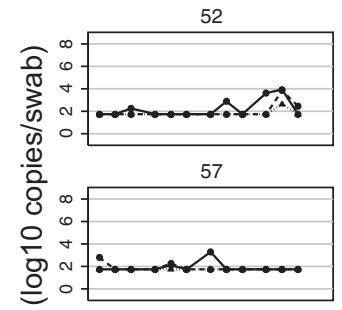

60
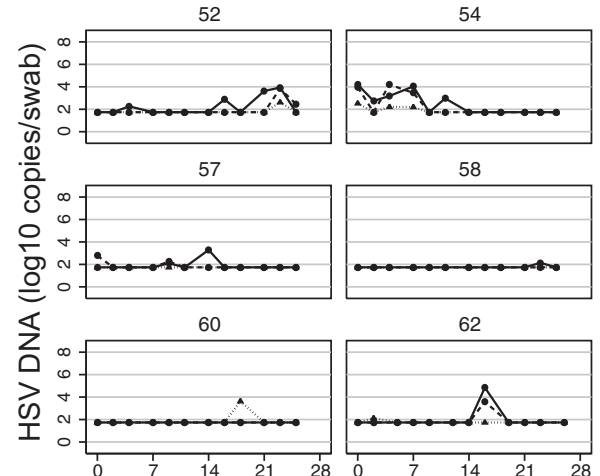

62

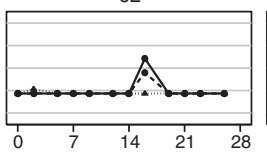

Day of follow-up
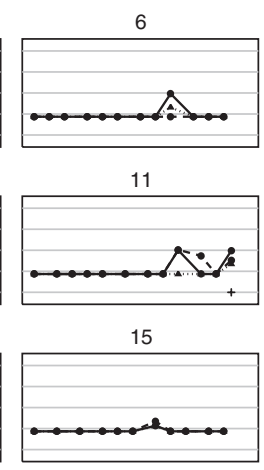

23

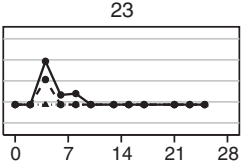

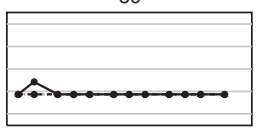

63

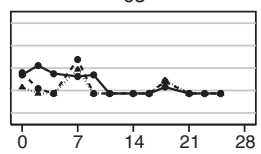

Vaginal Ulcer

B Acyclovir arm
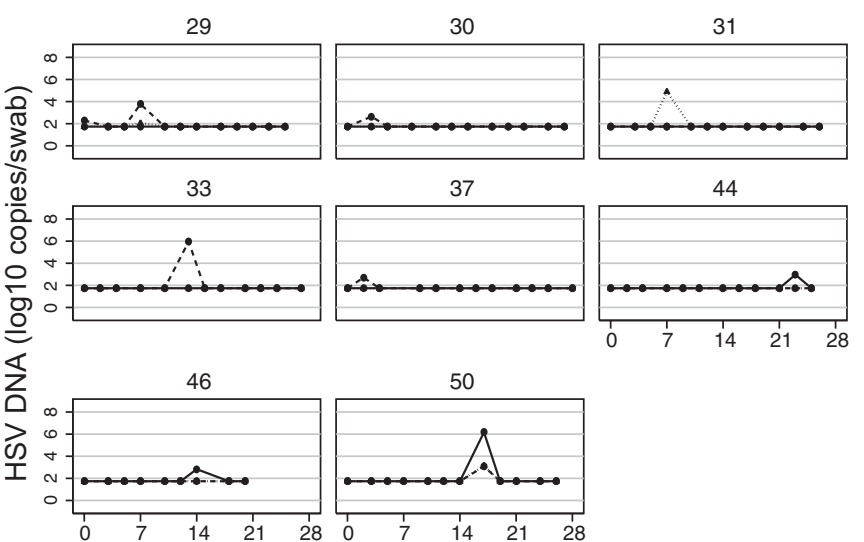

HIV Positive
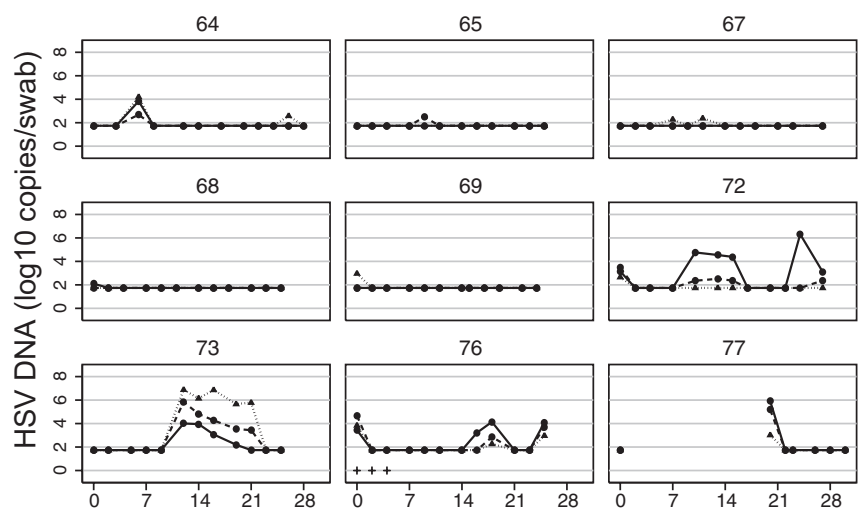

77

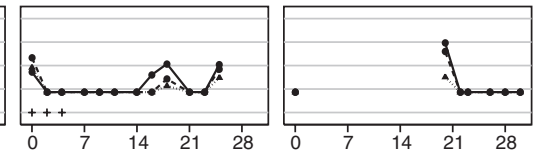

Day of follow-up

Figure 1 Quantity of cervical, vaginal and perineal/perianal herpes simplex virus (HSV) DNA detected at each visit for each woman with at least one visit with detectable HSV DNA. (A) Placebo arm and (B) acyclovir arm.

participants 10 and 25 had protracted periods of subclinical HSV shedding with high viral loads following similar trends at all anatomical sites. In other women, for example, participants 16 and 60, viral shedding was short-lived, with low viral load at only one site. In general, multisite shedding was associated with higher mean viral loads (4.07 log vs 2.90 log; $\mathrm{p}<0.012$ ).

In contrast, in the acyclovir arm, 8/34 (33\%) of HIV-negative women and $9 / 14$ (64\%) of HIV-positive women had HSV detected from at least one swab during follow-up. Figure 2 shows the proportion of visits when HSV DNA was detected by HIV status and treatment arm. Among HIV-negative women, those on acyclovir tended to have less frequent shedding than those on placebo (OR 0.36 ; $95 \%$ CI 0.12 to 1.12 ). A similar trend was seen in HIV-positive women but the CI is wider because there were fewer women in the analysis (OR 0.60; 95\% CI 0.15 to 2.40). In HIV-negative women on acyclovir, all shedding episodes lasted only one visit (figure 1B) and only two out of nine episodes involved shedding at more than one site. In contrast, among HIV-positive women on acyclovir, shedding patterns were similar to women on placebo.

\section{DISCUSSION}

In this study we describe site-specific genital HSV shedding over 1 month in a population of HSV-2-seropositive Tanzanian women participating in a trial of HSV suppressive therapy with acyclovir $400 \mathrm{mg}$ twice a day. Overall, HSV shedding was mainly subclinical. HSV was most commonly shed from the external skin; however, in the placebo arm on $42 \%$ of days when HSV DNA was detected, shedding was from all sites. Shedding rates in HIV-negative women were $3 \%$ of days in women on acyclovir compared with $11 \%$ in women on placebo (OR 0.28 ; $95 \%$ CI 0.12 to 0.66 ). For HIV-positive women, the rates were $14 \%$ in the acyclovir arm and $19 \%$ in the placebo arm $(0.69 ; 95 \%$ CI 0.26 to 1.85 ).

We found similar shedding rates to studies in the USA. In HIV-negative women, in a study of valacyclovir to reduce HSV transmission, HSV DNA was detected on $11.4 \%$ of days from a swab collected from the cervicovaginal area, the vulva and the perianal area ${ }^{24}$ and on $9 \%$ of days from clinician-collected vaginal swabs in another study. ${ }^{12}$ Another US study, however, reported an overall shedding rate of $27.9 \%$ from swabs taken 


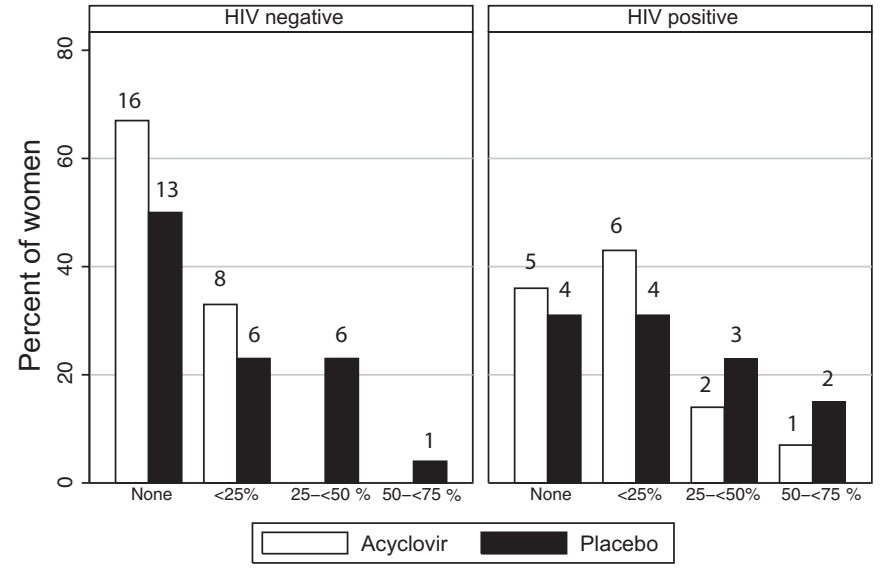

Figure 2 Association between treatment and frequency of herpes simplex virus DNA detection, by HIV status. Numbers indicate number of women.

from the cervicovaginal area (23\%) and vulva (23\%). ${ }^{25}$ One US study in HIV-positive women found HSV DNA on $19.2 \%$ of days from swabs taken from the vaginal-vulval and rectal area. ${ }^{26}$

Only two studies have reported longitudinal HSV shedding rates in sub-Saharan Africa and show similar results to our study. ${ }^{8} 10$ In 20 HIV-negative and 22 HIV-positive women in Burkina Faso who attended weekly visits for 4 weeks, HSV DNA was detected in cervicovaginal lavages on $9 \%$ and $21 \%$ of days, respectively. ${ }^{8}$ A study of 17 HIV-positive women in Kenya examined cervical HSV shedding rates over 1 month, and detected HSV DNA on $10 \%$ of days. ${ }^{10}$ Occasionally, very high prevalences of HSV shedding (22-43\%) have been reported by cross-sectional studies in sub-Saharan Africa. ${ }^{5} 7$

Among HIV-negative women, HSV shedding rates were lower overall and from each anatomical site in the acyclovir arm compared with the placebo arm. There was some evidence $(p=0.085)$ for an interaction between acyclovir and adherence among HIV-negative women, with a stronger effect being seen in those with adherence of $90 \%$ or greater. This contrasts with the trial findings, ${ }^{17}$ in which there was no evidence for an effect of acyclovir on HSV DNA detection overall, although there was a trend in good adherers. The substudy may have selected for better adherers by enrolling women who were still taking study tablets after 18 months and who were willing to attend frequent clinic visits. There was no clear evidence for a similar reduction in HIV-positive women, but fewer HIV-positive women were enrolled and there were too few women to stratify the analysis by adherence. Although the results are consistent with a beneficial effect of acyclovir in both HIV-negative and HIV-positive women as shedding was lower in the acyclovir arm in both strata of women, there was weak evidence that the effect of acyclovir differed in HIV-negative and HIV-positive women. It is possible that in HIV-positive women in this population, adherence to this regimen of acyclovir $400 \mathrm{mg}$ twice a day needs to be very high to suppress HSV shedding adequately.

Most women had HSV detected at least once, but there were few clinical HSV episodes. Similarly, few genital ulcers were recorded in the main trial. ${ }^{17} 20$ Clinical and subclinical recurrences decrease in frequency over time, ${ }^{27}{ }^{28}$ so most women may have acquired HSV-2 well before the substudy, and in all cases women had been infected for at least 18 months. In this setting, episodic therapy for genital ulcers as currently recommended by the WHO would have little impact on overall shedding rates.

Women were only seen three times per week, limiting our ability to describe the duration of shedding episodes. Recent data

\section{Key messages}

This is one of the first longitudinal studies to examine HSV shedding patterns in women in sub-Saharan Africa.

- In this cohort of women enrolled in a HSV suppressive therapy trial, HSV shedding was common and shedding patterns varied greatly by individual.

- HSV shedding rates were lower in the acyclovir arm in HIV-negative women.

- There was no clear effect of acyclovir in HIV-positive women.

from the USA suggest that over half of shedding episodes in immunocompetent adults last less than $6 \mathrm{~h}^{29}$ We observed a similar proportion of one visit episodes.

The study strengths include frequent sampling enabling detailed description of HSV shedding patterns, the sampling of multiple genital sites and high rates of follow-up. However, the following limitations should be considered. First, the number of women was low in the HIV-positive strata. Second, adherence estimates corresponded to a 3-month period and therefore may not always be a good estimate of adherence over the 1-month duration of this study. Adherence was estimated by pill count at booked visits and may be overestimated if tablets were discarded before visits. In addition, it was not possible to tell if participants were adhering to the 12 -hourly treatment schedule. Third, this is not a true randomised comparison between the placebo and acyclovir arms because participants were selected 18 months after randomisation based on other criteria. Finally, the study was conducted in remote areas. Swabs were stored dry, at $-20^{\circ} \mathrm{C}$ for up to 2 weeks before being transported to a $-80^{\circ} \mathrm{C}$ freezer. This may have led to a slight underestimation of shedding rates, but was unlikely to have substantially reduced rates of HSV DNA detection as our previous work showed no decrease in HSV DNA levels over 1 week in cervicovaginal lavages stored at $-20^{\circ} \mathrm{C} .{ }^{30}$

In summary, shedding was common but shedding patterns varied greatly by individual. Shedding rates were similar to two other longitudinal studies in Africa and to studies in non-African settings. In common with shedding studies in developed countries, most shedding episodes were asymptomatic. Among HIVnegative women, HSV shedding rates were lower in the acyclovir arm, while there was no clear effect in HIV-positive women.

Acknowledgements The authors would like to thank the women who participated in the study, the field team, headed by Charles Masalingi, for all their dedicated work and Cecile Lefebvre for her help with laboratory assays. They would also like to thank the Tanzanian Ministry of Health and Social Welfare and the National Institute for Medical Research for permission to conduct the study.

Funding This study was funded by the UK Medical Research Council (MRC, grant no G0400456). The trial within which it was nested was funded by the Wellcome Trust (grant no 066688), the UK Medical Research Council (MRC, grant no G0400456) and the UK Department for International Development.

\section{Competing interests None.}

Patient consent Obtained.

Ethics approval The study protocol was approved by the London School of Hygiene and Tropical Medicine ethics committee and the Medical Research Coordinating Committee of Tanzania.

Contributors CT, HAW, DWJ, JC, RJH and DAR designed the study. CT, DWJ and JC contributed to the data collection. JLG and LB advised on and oversaw the laboratory analyses. Statistical analyses were performed by CT with guidance from HAW, TCC and RJH. CT, HAW and DWJ wrote the initial draft of the paper. All authors contributed to the interpretation of the results and the revision of the manuscript.

Provenance and peer review Not commissioned; externally peer reviewed. 


\section{REFERENCES}

1. Corey L, Wald A, Celum CL, et al. The effects of herpes simplex virus-2 on HIV-1 acquisition and transmission: a review of two overlapping epidemics. J Acquir Immune Defic Syndr 2004;35:435-45.

2. Benedetti J, Corey L, Ashley R. Recurrence rates in genital herpes after symptomatic first-episode infection. Ann Intern Med 1994;121:847-54.

3. Wald A, Zeh J, Selke S, et al. Reactivation of genital herpes simplex virus type 2 infection in asymptomatic seropositive persons. N Engl J Med 2000:342:844-50.

4. Schacker T, Ryncarz AJ, Goddard J, et al. Frequent recovery of HIV-1 from genital herpes simplex virus lesions in HIV-1-infected men. JAMA 1998;280:61-6.

5. Mbopi-Keou FX, Gresenguet G, Mayaud P, et al. Interactions between herpes simplex virus type 2 and human immunodeficiency virus type 1 infection in African women: opportunities for intervention. J Infect Dis 2000;182:1090-6.

6. Augenbraun M, Feldman J, Chirgwin K, et al. Increased genital shedding of herpes simplex virus type 2 in HIV-seropositive women. Ann Intern Med 1995;123:845-7.

7. Baeten JM, McClelland RS, Corey L, et al. Vitamin A supplementation and genital shedding of herpes simplex virus among HIV-1-infected women: a randomized clinical trial. J Infect Dis 2004:189:1466-71.

8. Nagot N, Foulongne V, Becquart P, et al. Longitudinal assessment of HIV-1 and HSV-2 shedding in the genital tract of West African women. J Acquir Immune Defic Syndr 2005;39:632-4.

9. Mostad SB, Kreiss JK, Ryncarz AJ, et al. Cervical shedding of herpes simplex virus in human immunodeficiency virus-infected women: effects of hormonal contraception, pregnancy, and vitamin A deficiency. J Infect Dis 2000;181:58-63.

10. Mostad SB, Kreiss JK, Ryncarz A, et al. Cervical shedding of herpes simplex virus and cytomegalovirus throughout the menstrual cycle in women infected with human immunodeficiency virus type 1. Am J Obstet Gynecol 2000;183:948-55.

11. Ozouaki F, Ndjoyi-Mbiguino A, Legoff J, et al. Genital shedding of herpes simplex virus type 2 in childbearing-aged and pregnant women living in Gabon. Int J STD AIDS 2006;17:124-7.

12. Cherpes TL, Melan MA, Kant JA, et al. Genital tract shedding of herpes simplex virus type 2 in women: effects of hormonal contraception, bacterial vaginosis, and vaginal group B Streptococcus colonization. Clin Infect Dis 2005;40:1422-8.

13. WHO. Guidelines for the management of sexually transmitted infections. Geneva: World Health Organization, 2003. http://www.who.int/hiv/pub/sti/en/ STIGuidelines2003.pdf (accessed August 2009).

14. Mayaud P, Legoff J, Weiss HA, et al. Impact of acyclovir on genital and plasma HIV-1 RNA, genital herpes simplex virus type 2 DNA, and ulcer healing among HIV-1infected African women with herpes ulcers: a randomized placebo-controlled trial. $J$ Infect Dis 2009;200:216-26.
15. Paz-Bailey G, Sternberg M, Puren AJ, et al. Improvement in healing and reduction in HIV shedding with episodic acyclovir therapy as part of syndromic management among men: a randomized, controlled trial. J Infect Dis 2009;200:1039-49.

16. Phiri S, Hoffman IF, Weiss HA, et al. Impact of aciclovir on ulcer healing, lesional, genital and plasma HIV-1 RNA among patients with genital ulcer disease in Malawi. Sex Transm Infect 2010:86:345-52.

17. Watson-Jones D, Weiss HA, Rusizoka M, et al. Effect of herpes simplex suppression on incidence of HIV among women in Tanzania. N Engl J Med 2008:358:1560-71.

18. Celum C, Wald A, Hughes J, et al. Effect of aciclovir on HIV-1 acquisition in herpes simplex virus 2 seropositive women and men who have sex with men: a randomised, double-blind, placebo-controlled trial. Lancet 2008;371:2109-19.

19. Celum C, Wald A, Lingappa JR, et al. Acyclovir and transmission of HIV-1 from persons infected with HIV-1 and HSV-2. N Engl J Med 2010;362:427-39.

20. Tanton C, Weiss HA, Rusizoka M, et al. Long-term impact of acyclovir suppressive therapy on genital and plasma HIV RNA in Tanzanian women: a randomized controlled trial. J Infect Dis 2010;201:1285-97.

21. Mostad SB, Jackson S, Overbaugh J, et al. Cervical and vaginal shedding of human immunodeficiency virus type 1-infected cells throughout the menstrual cycle. J Infect Dis 1998;178:983-91.

22. Kessler HH, Muhlbauer G, Rinner B, et al. Detection of herpes simplex virus DNA by real-time PCR. J Clin Microbiol 2000;38:2638-42.

23. Magaret AS, Johnston C, Wald A. Use of the designation "shedder" in mucosal detection of herpes simplex virus DNA involving repeated sampling. Sex Transm Infect 2009;85:270-5.

24. Corey L, Wald A, Patel R, et al. Once-daily valacyclovir to reduce the risk of transmission of genital herpes. N Engl J Med 2004;350:11-20.

25. Wald A, Corey L, Cone $\mathrm{R}$, et al. Frequent genital herpes simplex virus 2 shedding in immunocompetent women. Effect of acyclovir treatment. J Clin Invest 1997;99:1092-7.

26. Augenbraun M, Corey L, Reichelderfer $\mathrm{P}$, et al. Herpes simplex virus shedding and plasma human immunodeficiency virus RNA levels in coinfected women. Clin Infect Dis 2001;33:885-90.

27. Wald A, Zeh J, Selke S, et al. Virologic characteristics of subclinical and symptomatic genital herpes infections. N Engl J Med 1995:333:770-5.

28. Benedetti JK, Zeh J, Corey L. Clinical reactivation of genital herpes simplex virus infection decreases in frequency over time. Ann Intern Med 1999;131:14-20.

29. Mark KE, Wald A, Magaret AS, et al. Rapidly cleared episodes of herpes simplex virus reactivation in immunocompetent adults. J Infect Dis 2008;198:1141-9.

30. Legoff $\mathbf{J}$, Tanton $\mathrm{C}$, Lecerf $\mathrm{M}$, et al. Influence of storage temperature on the stability of HIV-1 RNA and HSV-2 DNA in cervicovaginal secretions collected by vaginal washing. J Virol Methods 2006;138:196-200. 